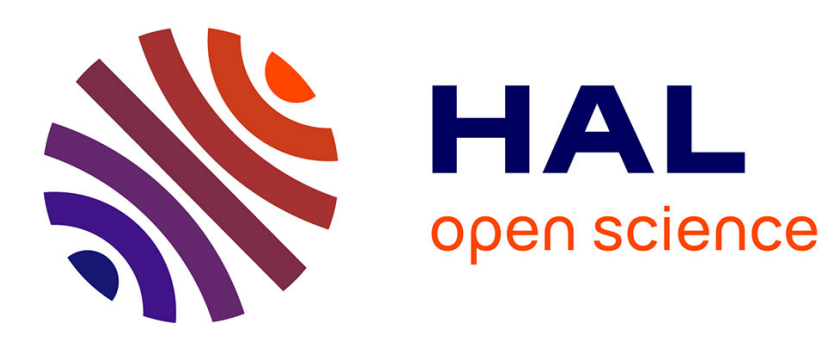

\title{
Cardioprotective effects of omega 3 fatty acids: origin of the variability
}

Jérôme Roy, Jean-Yves Le Guennec

\section{To cite this version:}

Jérôme Roy, Jean-Yves Le Guennec. Cardioprotective effects of omega 3 fatty acids: origin of the variability. Journal of Muscle Research and Cell Motility, 2017, 38 (1), pp.25 - 30. 10.1007/s10974016-9459-z . hal-01822215

\section{HAL Id: hal-01822215 \\ https://hal.umontpellier.fr/hal-01822215}

Submitted on 20 Dec 2019

HAL is a multi-disciplinary open access archive for the deposit and dissemination of scientific research documents, whether they are published or not. The documents may come from teaching and research institutions in France or abroad, or from public or private research centers.
L'archive ouverte pluridisciplinaire HAL, est destinée au dépôt et à la diffusion de documents scientifiques de niveau recherche, publiés ou non, émanant des établissements d'enseignement et de recherche français ou étrangers, des laboratoires publics ou privés. 


\section{Environmental parameters}

(13 PUFAs have pleiotropic actions including cardioprotective effects, especially against post-infarction arrhythmias (Saravanan et al. 2010; Schuchardt et al. 2011) Recently, new drugs have been added to the standard treatment of cardiac pathologies, such as statins. The introduction of statins, a drug class used to lower LDLcholesterol level by inhibiting HMG-COA reductase, can modulate $\omega 3$ PUFAs effects by interfering with their metabolism (de Lorgeril et al. 2013). The mechanism of action is still not well understood, but it seems that mitochondria could be involved, especially coenzyme Q10. In agreement with this hypothesis, a European secondary prevention clinical trial reports that $\omega 3$ supplementation (alpha-linolenic acid, Eicosapentaenoic acid; EPA and docoxahexaenoic acid; DHA) reduces the incidence of cardiovascular events by half only when statins were not prescribed (Eussen et al. 2012). Surprisingly, $\omega 3$ PUFAs cardioprotective effects are still observed in diabetic patients on statins (Kromhout et al. 2011), the same applies for the effects of $\omega 3$ PUFAs heart rate (Kim et al. 2011), on plasmatic triglyceride level and on the threshold of occurrence of ventricular palpitations induced by electrical stimulation (Durrington et al. 2001; Schrepf et al. 2004; ORIGIN Trial Investigators et al. 2012). An inhibition of 03 PUFAs effects by statins cannot be simply explained by loss of efficiency of these lipids, which was demonstrated by the most recent clinical trials and meta-analysis. For example, in a diabetic population, it is possible to have a metabolic pathway altered by this pathology, which is sensitive to $\omega 3$ PUFAs and not to statins and vice versa.

Also, patients included in randomized clinical trials (RCT) using 13 PUFAs can differ from the general population in an important way, which could explain the various results between RCTs (where there is intervention) and epidemiological studies. It was reported that patients who volunteered to join RCTs are frequently healthier and more active than the average population, which could affect the results in an unknown way. Furthermore, patients dropping out of the trials are often more ill and could be the ones benefiting most from $\omega 3$ PUFAs.

Nutritionally, cooking method are of importance. Consuming boiled fish is associated with a lower rate of fatal arrhythmias when compared to fried fish consumption (Mozaffarian et al. 2003). Also, mortality linked to coronary heart disease was lower in individuals consuming oily fish as opposed to white meat fish or no fish at all (Oomen et al. 2000).

The AHA nutrition recommendations advise to limit oily fish consumption of children. Indeed, fat fishes, such as farmed salmon, swordfish, king mackerel, or tilefish, are known to accumulate high levels of mercury, polychlorinated biphenyls, dioxins, organochlorines and other environmental contaminants (Hites et al. 2004). The levels of these substances are generally higher in older, larger, predatory fishes and marine mammals. Also, although a high rate of plasmatic DHA was associated with a reduction of the acute coronary artery events, this effect is significantly attenuated when increased levels of mercury are found in patient's hair (Rissanen et al. 2000), suggesting an interaction between $\omega 3$ PUFAs and mercury. Also, it was suggested that a high intake of mercury from non-oily freshwater fish and the subsequent mercury accumulation in the body were associated with a higher an risk of myocardial infarction in Eastern Finnish men and this increased risk may be due to the promotion of lipid peroxidation by mercury (Salonen et al. 1995). More recently, $\mathrm{Hu}$ et al. (2016) studied the relationship between Canadian Inuit traditional diet and myocardial infarction risk in 2072 participants aged 18-79. They found that Inuit traditional diet contains high levels of EPA, DHA and mercury. A careful analysis of their results indicates that beneficial effects of EPA and DHA on myocardial infarction are diminished by the adverse effect of mercury (by $5 \%$ for men and $4 \%$ for women) (Hu et al. 2016). Thus, dietary mercury levels could partially explain certain contradictory results.

Finally, an important factor that is rarely taken into account in these studies is the inter-individual variability of incorporation of $\omega 3$ PUFAs in cell membranes (Arterburn et al. 2006; Bougnoux et al. 2009). In 2010, it has been shown that cardioprotective properties of $\omega 3$ PUFAs depend on their incorporation into cell membranes (von Schacky 2010), which suggests that positive effects needing incorporation can be masked in a sub-population which do not efficiently incorporate $\omega 3$ PUFAs in their cell membrane.

\section{Cellular parameters}

The controversy about 13 PUFAs effects also extends to the cellular level (Billman 2013). The majority of electrophysiological single cell studies found an inhibition of ion currents such as fast sodium current $\left(\mathrm{I}_{\mathrm{Na}}\right)$ (Xiao et al. 1995; Kang and Leaf 1996; Leifert et al. 2000), ultrafast activating delayed outward potassium current ( $\mathrm{I}_{\mathrm{Kur}}$ ) (Honoré et al. 1994; Li et al. 2009), rapidly activating delayed rectifying outward potassium current $\left(\mathrm{I}_{\mathrm{KR}}\right)$ (Guizy et al. 2005), L-type calcium current ( $\mathrm{I}_{\mathrm{CaL}}$ ) (Xiao et al. 1997; Hazama et al. 1998; Rodrigo et al. 1999; Ferrier et al. 2002; Verkerk et al. 2006), and $\mathrm{Na}^{+}-\mathrm{Ca}^{2+}$ exchanger current ( $\mathrm{I}_{\mathrm{NCX}}$ ) (Xiao et al. 2004; Ander et al. 2007). On the other hand, $\omega 3$ PUFAs were found to enhance slowly activating 
delayed rectifying outward potassium current $\left(\mathrm{I}_{\mathrm{KS}}\right)$ (Doolan et al. 2002) and outwardly rectifying potassium current ( $\mathrm{I}_{\mathrm{TO}}$ ) (Macleod et al. 1998; Judé et al. 2003; Li et al. 2009). Also, incorporation of $\omega 3$ PUFAs has been positively correlated with mitochondrial proton leak (Hulbert 2003), and increased mitochondrial DHA content through lipid infusion or dietary intervention augments proton movement and state 4 respiration (Stillwell et al. 1997). In addition, DHA enhances $\mathrm{Na}^{+}$membrane permeability (Stillwell and Wassall 2003) and $\mathrm{Na}^{+} / \mathrm{K}^{+}$-ATPase activity (Else and Wu 1999; Turner et al. 2003; Wu et al. 2004).

Collectively, these studies have led to the idea that $\omega 3$ PUFAs influence mitochondrial activity, and excitationcontraction coupling through modulation of ion channels. However, it is surprising that in a lot of epidemiological studies, if not all, no effects on electrocardiogram parameters were observed in agreement with such molecular effects as it is observed with drugs having comparable multi-ion channels effects.

Such contradictory and unspecific effects of $\omega 3$ PUFAs on ion membrane channels activity challenge the hypothesis that cardioprotective effects of 133 PUFA could be due to the modulation of these channels or that in vivo, $\omega 3$ PUFAs have any effect on ion channels.

In parallel, some scientists were more interested in the regulation of intracellular $\mathrm{Ca}^{2+}$, which is known to play a role in physio-pathological situations and to be a key actor in cardiac muscle and skeletal excitation-contraction coupling.

Acute application of $\omega 3$ PUFAs leads to numerous effects on intracellular $\mathrm{Ca}^{2+}$ and on cellular mechanisms that ensue from it (Judé et al. 2006; Billman 2012). Besides the fact that $\omega 3$ PUFAs inhibit many voltage-dependent calcium channels activity, it has also been shown that they inhibit pro-arrhythmic diastolic depolarization due to intracellular calcium elevation and this can be explained by a reduction of NCX exchanger activity (Szentandrássy et al. 2007; Berecki et al. 2007; Den Ruijter et al. 2008; Sankaranarayanan and Venetucci 2012).

03 PUFAs have direct effects on mechanisms that regulate sarcoplasmic $\mathrm{Ca}^{2+}$ level by decreasing $\mathrm{Ca}^{2+}$ released by the sarcoplasmic reticulum. Mechanistically, a decreased frequency of the occurrence of spontaneous calcium events (sparks) in isolated ventricular cardiomyocytes has been observed (Negretti et al. 2000; O'Neill et al. 2002; Honen et al. 2003; Sankaranarayanan and Venetucci 2012). In agreement with this observation, $\omega 3$ PUFAs reduce the opening probability of ryanodine receptor type 2 (RyR2), responsible for these calcium events (Swan et al. 2003). In 1993, Taffet observed that a $\omega 3$ PUFAs-enriched diet is associated with increased DHA incorporation in the cardiac sarcoplasmic reticulum membrane (Taffet et al. 1993). This effect is associated with a reduction of sarcoplasmic reticulum content and a decreased SERCA2a pump activity by dietary interventions that change the composition, and possibly the structure of phospholipid membranes thereby affecting enzyme turnover. However, these observations are in contradiction with other studies (Leifert et al. 2000; Billman et al. 2012). It must be noted that the acute application of $\omega 3$ PUFAs induces an augmentation of the sarcoplasmic reticulum calcium content (Negretti et al. 2000; O'Neill et al. 2002; Swan et al. 2003). Also, delayed afterdepolarization and early after-depolarization are both prevented by an acute or chronic exposition to 13 PUFAs (Den Ruijter et al. 2008; Milberg et al. 2011).

In conclusion, $\omega 3$ PUFAs can regulate intracellular $\mathrm{Ca}^{2+}$ homeostasis, decreasing the risk of arrhythmias, in particular when these originate from a change of intracellular $\mathrm{Ca}^{2+}$ homeostasis such as during an ischemia/reperfusion episode (Billman 1991).

Dietary supplementation with $\omega 3$ PUFAs leads to their incorporation in cardiac membrane phospholipids. This incorporation in mitochondria, sarcoplasmic reticulum and cell membranes plays an essential role in the regulation of excitation-contraction coupling. Thus, several studies have investigated the effects of this incorporation. One important point is that after their incorporation, these lipids can undergo enzymatic and non-enzymatic oxidation, leading to new products derived from $\omega 3$ PUFAs. The effects of enzymatic metabolites such as prostaglandins or leukotrienes have been well studied (Calder 2010). However, it is important to note that in presence of a lipid antioxidant, alpha-tocopherol, the beneficial effects of $\omega 3$ PUFAs are totally abolished (such as anti-arrhythmic properties) whereas in presence of a pro-oxidant (low concentrations of hydrogen peroxide) enhancing non-enzymatic oxidation, the beneficial effects of these lipids are potentiated (Roy et al. 2015). This might be linked with a similar observation about the effects of DHA on rat ion currents (Judé et al. 2003). Recently, we focused our attention on certain non-enzymatic metabolites of $\omega 3$ PUFAs (NEO-PUFAs). We found that some NEO-PUFAs, namely the 4(RS)-4- $\mathrm{F}_{4 \mathrm{t}^{-}}$ neuroprostanes and the $10(\mathrm{~S})-10-\mathrm{F}_{4 \mathrm{t}}$-neuroprostane, can normalize RyR2 function and thus reduce the occurrence of abnormal extrasystoles (Roy et al. 2015). These results, and others, suggest that the beneficial effects of $\omega 3$ PUFAs can be obtained in conditions of oxidative stress (characteristic of many chronic pathologies).

Also, these discoveries open new perspectives for nonenzymatic oxygenated metabolites of $\omega 3$ PUFAs as potent healthy mediators in diseases associated with an oxidative stress (Burton et al. 1990; Janero et al. 1991; Sano 2010; Anderson and Taylor 2012; Anderson et al. 2012).

This element of oxidation must be taken into account, because it differs from one individual to another. The intensity of oxidative stress and antioxidant capacity are highly inter-individually different, thus even for a 
comparable level of PUFAs, the production of NEOPUFAs will be variable.

\section{Conclusion}

To conclude, all these contradictory data leads the scientific community to consider effects and cellular targets of 13 PUFAs (acutely or chronically applied).

Recently, it has been found that low $\omega 3$ PUFAs blood level and dietary intake can potentially increase the risk of non beneficial outcomes and could explain the difference and the contradiction in the effects observed (Stark et al. 2016).

Many factors can explain the contradictory observations made in cells, animal and human studies as described in this review.

Therefore, it is important and essential to take into consideration these parameters in future studies that, otherwise, could generate other contradictory results. Notably, given the challenges of fatty acid analysis and reporting, an international initiative should be considered to lead to standardized approaches and methods before all studies. To limit the conflicting findings, a standardization of study method (taking into account dose and type of fatty acids, rate of oxidation) should be proposed such as the 63 PUFAs index proposed by Von Schacky (von Schacky 2010).

\section{References}

Ander BP, Hurtado C, Raposo CS et al (2007) Differential sensitivities of the NCX1.1 and NCX1.3 isoforms of the $\mathrm{Na}^{+}{ }_{-}$ $\mathrm{Ca}^{2+}$ exchanger to alpha-linolenic acid. Cardiovasc Res 73:395-403. doi:10.1016/j.cardiores.2006.09.013

Anderson EJ, Taylor DA (2012) Stressing the heart of the matter: rethinking the mechanisms underlying therapeutic effects of n-3 polyunsaturated fatty acids. F1000 Med Rep 4:13. doi:10.3410/ M4-13

Anderson EJ, Katunga LA, Willis MS (2012) Mitochondria as a source and target of lipid peroxidation products in healthy and diseased heart. Clin Exp Pharmacol Physiol 39:179-193. doi:10. 1111/j.1440-1681.2011.05641.x

Arterburn LM, Hall EB, Oken H (2006) Distribution, interconversion, and dose response of $\mathrm{n}-3$ fatty acids in humans. Am $\mathbf{J}$ Clin Nutr 83:1467S-1476S

Ascherio A, Rimm EB, Stampfer MJ et al (1995) Dietary intake of marine n-3 fatty acids, fish intake, and the risk of coronary disease among men. N Engl J Med 332:977-982. doi:10.1056/ NEJM199504133321501

Bang HO, Dyerberg J, Hjøorne N (1976) The composition of food consumed by Greenland Eskimos. Acta Med Scand 200:69-73

Berecki G, Den Ruijter HM, Verkerk AO et al (2007) Dietary fish oil reduces the incidence of triggered arrhythmias in pig ventricular myocytes. Heart Rhythm 4:1452-1460. doi:10.1016/j.hrthm. 2007.07.015

Billman GE (1991) The antiarrhythmic and antifibrillatory effects of calcium antagonists. J Cardiovasc Pharmacol 18(Suppl 10):S107-S117
Billman GE (2012) Omega-3 polyunsaturated fatty acids and cardiac rhythm: an introduction. Front Physiol 3:457. doi:10.3389/fphys. 2012.00457

Billman GE (2013) The effects of omega-3 polyunsaturated fatty acids on cardiac rhythm: a critical reassessment. Pharmacol Ther 140:53-80. doi:10.1016/j.pharmthera.2013.05.011

Billman GE, Carnes CA, Adamson PB et al (2012) Dietary omega-3 fatty acids and susceptibility to ventricular fibrillation: lack of protection and a proarrhythmic effect. Circ Arrhythm Electrophysiol 5:553-560. doi:10.1161/CIRCEP.111.966739

Bougnoux P, Hajjaji N, Ferrasson MN et al (2009) Improving outcome of chemotherapy of metastatic breast cancer by docosahexaenoic acid: a phase II trial. $\mathrm{Br} \mathrm{J}$ Cancer 101:1978-1985. doi:10.1038/sj.bjc.6605441

Burr ML, Fehily AM, Gilbert JF et al (1989) Effects of changes in fat, fish, and fibre intakes on death and myocardial reinfarction: diet and reinfarction trial (DART). Lancet 2:757-761

Burton KP, Morris AC, Massey KD et al (1990) Free radicals alter ionic calcium levels and membrane phospholipids in cultured rat ventricular myocytes. J Mol Cell Cardiol 22:1035-1047

Calder PC (2010) Omega-3 fatty acids and inflammatory processes. Nutrients 2:355-374. doi:10.3390/nu2030355

De Caterina R (2011) n-3 fatty acids in cardiovascular disease. N Engl J Med 364:2439-2450. doi:10.1056/NEJMra1008153

de Lorgeril M, Salen P, Defaye P, Rabaeus M (2013) Recent findings on the health effects of omega- 3 fatty acids and statins, and their interactions: do statins inhibit omega-3? BMC Med 11:5. doi:10. 1186/1741-7015-11-5

Den Ruijter HM, Berecki G, Verkerk AO et al (2008) Acute administration of fish oil inhibits triggered activity in isolated myocytes from rabbits and patients with heart failure. Circulation 117:536-544. doi:10.1161/CIRCULATIONAHA.107. 733329

Doolan GK, Panchal RG, Fonnes EL et al (2002) Fatty acid augmentation of the cardiac slowly activating delayed rectifier current (IKs) is conferred by hminK. FASEB J 16:1662-1664. doi:10.1096/fj.02-0084fje

Durrington PN, Bhatnagar D, Mackness MI et al (2001) An omega-3 polyunsaturated fatty acid concentrate administered for one year decreased triglycerides in simvastatin treated patients with coronary heart disease and persisting hypertriglyceridaemia. Heart Br Card Soc 85:544-548

Else PL, Wu BJ (1999) What role for membranes in determining the higher sodium pump molecular activity of mammals compared to ectotherms? J Comp Physiol B 169:296-302

Eussen SRBM, Geleijnse JM, Giltay EJ et al (2012) Effects of n-3 fatty acids on major cardiovascular events in statin users and non-users with a history of myocardial infarction. Eur Heart J 33:1582-1588. doi:10.1093/eurheartj/ehr499

Ferrier GR, Redondo I, Zhu J, Murphy MG (2002) Differential effects of docosahexaenoic acid on contractions and L-type $\mathrm{Ca}^{2+}$ current in adult cardiac myocytes. Cardiovasc Res 54:601-610

Gillum RF, Mussolino M, Madans JH (2000) The relation between fish consumption, death from all causes, and incidence of coronary heart disease. The NHANES I epidemiologic follow-up study. J Clin Epidemiol 53:237-244

Guallar E, Aro A, Jiménez FJ et al (1999) Omega-3 fatty acids in adipose tissue and risk of myocardial infarction: the EURAMIC study. Arterioscler Thromb Vasc Biol 19:1111-1118

Guizy M, Arias C, David M et al (2005) \{Omega\}-3 and \{omega\}-6 polyunsaturated fatty acids block HERG channels. Am J Physiol Cell Physiol 289:C1251-C1260. doi:10.1152/ajpcell.00036.2005

Hazama H, Nakajima T, Asano M et al (1998) Omega-3 polyunsaturated fatty acids-modulation of voltage-dependent L-type $\mathrm{Ca}^{2+}$ current in guinea-pig tracheal smooth muscle cells. Eur J Pharmacol 355:257-266 
Hites RA, Foran JA, Carpenter DO et al (2004) Global assessment of organic contaminants in farmed salmon. Science 303:226-229. doi: $10.1126 /$ science. 1091447

Honen BN, Saint DA, Laver DR (2003) Suppression of calcium sparks in rat ventricular myocytes and direct inhibition of sheep cardiac RyR channels by EPA, DHA and oleic acid. J Membr Biol 196:95-103. doi:10.1007/s00232-003-0628-9

Honoré E, Barhanin J, Attali B et al (1994) External blockade of the major cardiac delayed-rectifier $\mathrm{K}^{+}$channel (Kv1.5) by polyunsaturated fatty acids. Proc Natl Acad Sci USA 91:1937-1941

Hu XF, Laird BD, Chan HM (2016) Mercury diminishes the cardiovascular protective effect of omega-3 polyunsaturated fatty acids in the modern diet of Inuit in Canada. Environ Res. doi:10.1016/j.envres.2016.06.001

Hulbert AJ (2003) Life, death and membrane bilayers. J Exp Biol 206:2303-2311

Iso $\mathrm{H}$, Kobayashi $\mathrm{M}$, Ishihara $\mathrm{J}$ et al (2006) Intake of fish and $\mathrm{n} 3$ fatty acids and risk of coronary heart disease among Japanese: the Japan public health center-based (JPHC) study cohort I. Circulation 113:195-202. doi:10.1161/CIRCULATIONAHA.105.581355

Janero DR, Hreniuk D, Sharif HM (1991) Hydrogen peroxide-induced oxidative stress to the mammalian heart-muscle cell (cardiomyocyte): lethal peroxidative membrane injury. J Cell Physiol 149:347-364. doi:10.1002/jcp.1041490302

Judé S, Bedut S, Roger S et al (2003) Peroxidation of docosahexaenoic acid is responsible for its effects on ITO and ISS in rat ventricular myocytes. Br J Pharmacol 139:816-822. doi:10. 1038/sj.bjp.0705308

Judé S, Roger S, Martel E et al (2006) Dietary long-chain omega-3 fatty acids of marine origin: a comparison of their protective effects on coronary heart disease and breast cancers. Prog Biophys Mol Biol 90:299-325. doi:10.1016/j.pbiomolbio.2005. 05.006

Kang JX, Leaf A (1996) Evidence that free polyunsaturated fatty acids modify $\mathrm{Na}^{+}$channels by directly binding to the channel proteins. Proc Natl Acad Sci USA 93:3542-3546

Kim S-H, Kim M-K, Lee H-Y et al (2011) Prospective randomized comparison between omega-3 fatty acid supplements plus simvastatin versus simvastatin alone in Korean patients with mixed dyslipidemia: lipoprotein profiles and heart rate variability. Eur J Clin Nutr 65:110-116. doi:10.1038/ejen.2010.195

Kromhout D, Bloemberg BP, Feskens EJ et al (1996) Alcohol, fish, fibre and antioxidant vitamins intake do not explain population differences in coronary heart disease mortality. Int $\mathbf{J}$ Epidemiol 25:753-759

Kromhout D, Geleijnse JM, de Goede J et al (2011) n-3 fatty acids, ventricular arrhythmia-related events, and fatal myocardial infarction in postmyocardial infarction patients with diabetes. Diabetes Care 34:2515-2520. doi:10.2337/dc11-0896

Leifert WR, Jahangiri A, Saint DA, McMurchie EJ (2000) Effects of dietary $\mathrm{n}-3$ fatty acids on contractility, $\mathrm{Na}^{+}$and $\mathrm{K}^{+}$currents in a rat cardiomyocyte model of arrhythmia. J Nutr Biochem 11:382-392

Li G-R, Sun H-Y, Zhang X-H et al (2009) Omega-3 polyunsaturated fatty acids inhibit transient outward and ultra-rapid delayed rectifier $\mathrm{K}^{+}$currents and $\mathrm{Na}^{+}$current in human atrial myocytes. Cardiovasc Res 81:286-293. doi:10.1093/cvr/cvn322

Macleod JC, Macknight AD, Rodrigo GC (1998) The electrical and mechanical response of adult guinea pig and rat ventricular myocytes to omega3 polyunsaturated fatty acids. Eur $\mathbf{J}$ Pharmacol 356:261-270

Milberg P, Frommeyer G, Kleideiter A et al (2011) Antiarrhythmic effects of free polyunsaturated fatty acids in an experimental model of LQT2 and LQT3 due to suppression of early afterdepolarizations and reduction of spatial and temporal dispersion of repolarization. Heart Rhythm 8:1492-1500. doi: $10.1016 /$ j.hrthm.2011.03.058

Mozaffarian D, Lemaitre RN, Kuller LH et al (2003) Cardiac benefits of fish consumption may depend on the type of fish meal consumed: the cardiovascular health study. Circulation 107:1372-1377

Negretti N, Perez MR, Walker D, O’Neill SC (2000) Inhibition of sarcoplasmic reticulum function by polyunsaturated fatty acids in intact, isolated myocytes from rat ventricular muscle. J Physiol 523(Pt 2):367-375

O'Neill SC, Perez MR, Hammond KE et al (2002) Direct and indirect modulation of rat cardiac sarcoplasmic reticulum function by $n-3$ polyunsaturated fatty acids. J Physiol 538:179-184

Oomen CM, Feskens EJ, Räsänen L et al (2000) Fish consumption and coronary heart disease mortality in Finland, Italy, and The Netherlands. Am J Epidemiol 151:999-1006

Pietinen P, Ascherio A, Korhonen P et al (1997) Intake of fatty acids and risk of coronary heart disease in a cohort of Finnish men. The alpha-tocopherol, beta-carotene cancer prevention study. Am J Epidemiol 145:876-887

Rissanen T, Voutilainen S, Nyyssönen K et al (2000) Fish oil-derived fatty acids, docosahexaenoic acid and docosapentaenoic acid, and the risk of acute coronary events: the Kuopio ischaemic heart disease risk factor study. Circulation 102:2677-2679

Rodrigo GC, Dhanapala S, Macknight AD (1999) Effects of eicosapentaenoic acid on the contraction of intact, and spontaneous contraction of chemically permeabilized mammalian ventricular myocytes. J Mol Cell Cardiol 31:733-743. doi:10. 1006/jmcc. 1998.0914

Roy J, Oger C, Thireau J et al (2015) Non-enzymatic lipid mediators, neuroprostanes, exert the anti-arrhythmic properties of docosahexaenoic acid. Free Radic Biol Med. doi:10.1016/j.freerad biomed.2015.04.014

Salonen JT, Seppänen K, Nyyssönen K et al (1995) Intake of mercury from fish, lipid peroxidation, and the risk of myocardial infarction and coronary, cardiovascular, and any death in eastern Finnish men. Circulation 91:645-655

Sankaranarayanan R, Venetucci L (2012) Are the anti-arrhythmic effects of omega-3 fatty acids due to modulation of myocardial calcium handling? Front Physiol 3:373. doi:10.3389/fphys.2012. 00373

Sano M (2010) Cardioprotection by hormetic responses to aldehyde. Circ J 74:1787-1793

Saravanan P, Bridgewater B, West AL et al (2010) Omega-3 fatty acid supplementation does not reduce risk of atrial fibrillation after coronary artery bypass surgery: a randomized, doubleblind, placebo-controlled clinical trial. Circ Arrhythm Electrophysiol 3:46-53. doi:10.1161/CIRCEP.109.899633

Schrepf R, Limmert T, Claus Weber P et al (2004) Immediate effects of $\mathrm{n}-3$ fatty acid infusion on the induction of sustained ventricular tachycardia. Lancet 363:1441-1442. doi:10.1016/ S0140-6736(04)16105-9

Schuchardt JP, Schneider I, Meyer H et al (2011) Incorporation of EPA and DHA into plasma phospholipids in response to different omega-3 fatty acid formulations-a comparative bioavailability study of fish oil versus krill oil. Lipids Health Dis 10:145. doi:10.1186/1476-511X-10-145

Siscovick DS, Raghunathan TE, King I et al (1995) Dietary intake and cell membrane levels of long-chain n-3 polyunsaturated fatty acids and the risk of primary cardiac arrest. JAMA 274:1363-1367

Stark KD, Van Elswyk ME, Higgins MR et al (2016) Global survey of the omega-3 fatty acids, docosahexaenoic acid and eicosapentaenoic acid in the blood stream of healthy adults. Prog Lipid Res 63:132-152. doi:10.1016/j.plipres.2016.05.001 
Stillwell W, Wassall SR (2003) Docosahexaenoic acid: membrane properties of a unique fatty acid. Chem Phys Lipids 126:1-27

Stillwell W, Jenski LJ, Crump FT, Ehringer W (1997) Effect of docosahexaenoic acid on mouse mitochondrial membrane properties. Lipids 32:497-506

Swan JS, Dibb K, Negretti N et al (2003) Effects of eicosapentaenoic acid on cardiac SR $\mathrm{Ca}\left({ }^{2+}\right)$-release and ryanodine receptor function. Cardiovasc Res 60:337-346. doi:10.1016/S00086363(03)00545-5

Szentandrássy N, Pérez-Bido MR, Alonzo E et al (2007) Protein kinase $A$ is activated by the $n-3$ polyunsaturated fatty acid eicosapentaenoic acid in rat ventricular muscle. J Physiol 582:349-358. doi:10.1113/jphysiol.2007.132753

Taffet GE, Pham TT, Bick DL et al (1993) The calcium uptake of the rat heart sarcoplasmic reticulum is altered by dietary lipid. J Membr Biol 131:35-42

Trial Investigators ORIGIN, Bosch J, Gerstein HC et al (2012) n-3 fatty acids and cardiovascular outcomes in patients with dysglycemia. N Engl J Med 367:309-318. doi:10.1056/ NEJMoa1203859

Turner N, Else PL, Hulbert AJ (2003) Docosahexaenoic acid (DHA) content of membranes determines molecular activity of the sodium pump: implications for disease states and metabolism. Naturwissenschaften 90:521-523. doi:10.1007/s00114-003-0470-z

Verkerk AO, van Ginneken ACG, Berecki G et al (2006) Incorporated sarcolemmal fish oil fatty acids shorten pig ventricular action potentials. Cardiovasc Res 70:509-520. doi:10.1016/j.cardiores. 2006.02.022 von Schacky C (2010) Omega-3 index and sudden cardiac death. Nutrients 2:375-388. doi:10.3390/nu2030375

Wilhelm M, Tobias R, Asskali F et al (2008) Red blood cell omega-3 fatty acids and the risk of ventricular arrhythmias in patients with heart failure. Am Heart J 155:971-977. doi:10.1016/j.ahj.2007. 11.045

Wu BJ, Hulbert AJ, Storlien LH, Else PL (2004) Membrane lipids and sodium pumps of cattle and crocodiles: an experimental test of the membrane pacemaker theory of metabolism. Am J Physiol Regul Integr Comp Physiol 287:R633-R641. doi:10.1152/ ajpregu.00549.2003

Xiao YF, Kang JX, Morgan JP, Leaf A (1995) Blocking effects of polyunsaturated fatty acids on $\mathrm{Na}+$ channels of neonatal rat ventricular myocytes. Proc Natl Acad Sci USA 92:11000-11004

Xiao YF, Gomez AM, Morgan JP et al (1997) Suppression of voltagegated L-type $\mathrm{Ca}^{2+}$ currents by polyunsaturated fatty acids in adult and neonatal rat ventricular myocytes. Proc Natl Acad Sci USA 94:4182-4187

Xiao Y-F, Ke Q, Chen Y et al (2004) Inhibitory effect of n-3 fish oil fatty acids on cardiac $\mathrm{Na}^{+} / \mathrm{Ca}^{2+}$ exchange currents in HEK293t cells. Biochem Biophys Res Commun 321:116-123. doi:10. 1016/j.bbrc.2004.06.114

Yamagishi K, Iso H, Date C et al (2008) Fish, omega-3 polyunsaturated fatty acids, and mortality from cardiovascular diseases in a nationwide community-based cohort of Japanese men and women the JACC (Japan collaborative cohort study for evaluation of cancer risk) study. J Am Coll Cardiol 52:988-996. doi:10.1016/j.jacc.2008.06.018 